\title{
Clinic characteristics of psoriasis in China: a nationwide survey in over 12000 patients
}

\author{
Kun Chen ${ }^{1}$, Gang Wang ${ }^{2}$, Hongzhong Jin ${ }^{3}$, Jinhua $X u^{4}$, Xuejun Zhu ${ }^{5}$, Min Zheng ${ }^{6}$ and \\ Heng Gu ${ }^{1}$ \\ ${ }^{1}$ Institute of Dermatology, Chinese Academy of Medical Sciences and Peking Union Medical College,Nanjing, Jiangsu, China \\ ${ }^{2}$ Department of Dermatology, Xijing Hospital, Fourth Military Medical University, Xi'an, Shanxi, China \\ ${ }^{3}$ Peking Union Medical Hospital, Chinese Academy of Medical Sciences and Peking Union Medical College, Peking, China \\ ${ }^{4}$ Department of Dermatology, Huashan Hospital, Fudan University, Shanghai, China \\ ${ }^{5}$ Department of Dermatology, Peking University First Hospital, Peking, China \\ ${ }^{6}$ Department of Dermatology, Second Affiliated Hospital, Zhejiang University, School of Medicine, Hangzhou, Zhejiang, China \\ Correspondence to: Heng Gu, email: guhengy@yahoo.com.cn \\ Min Zheng, email: minz@zju.edu.cn
}

Keywords: psoriasis, epidemiology, phenotype, Chinese Han

Received: November 17, $2016 \quad$ Accepted: April 29, $2017 \quad$ Published: June 12, 2017

Copyright: Chen et al. This is an open-access article distributed under the terms of the Creative Commons Attribution License 3.0 (CC BY 3.0), which permits unrestricted use, distribution, and reproduction in any medium, provided the original author and source are credited.

\section{ABSTRACT}

Psoriasis is a worldwide chronic inflammatory disease, involving both skin and joints. In order to characterize psoriasis in Han Chinese population, we conducted this nationwide prospective and hospital based survey, in which $\mathbf{5 6}$ hospitals with departments of dermatology participated, located in 33 cities across China. A total of 12,031 outpatients with psoriasis were registered during 2009 to 2010, which the data was collected by standard questionnaires. The main data acquisition included demographics, family history, disease status and other comorbidities. Physical and dermatological examination, including body surface area (BSA) and psoriasis area severity index (PASI) were applied to evaluate the disease severity. Descriptive statistics, 2 tailed $t$-test and chi-square test were used appropriately for the statistical analysis. From the study, we found that the male and female ratio of the patients was 1.49:1. Mean age of onset was $30.2 \pm 14.5$ years for males and $27.1 \pm 15.6$ years for females $(P<0.05)$. Scalp was the most common onset site $(52.8 \%)$, The mean PASI was $18.70 \pm 10.01$, indicating that most patients presenting at the hospitals had moderate-to-severe psoriasis and the majority was psoriasis vulgaris (96.5\%). Among 12,031 patients, $23.1 \%$ had a family history of psoriasis, $16.1 \%$ had comorbidities, and $29.9 \%$ had nail changes. The most important aggravation factor was season change $(60.2 \%)$, followed by psychological stress $(34.5 \%)$, and there significant differences between genders on trigger factors. In conclusion, this study characterizing psoriasis in Han Chinese population, could be used as basic data for future study.

\section{INTRODUCTION}

Psoriasis is a chronic inflammatory skin disease with a strong hereditary component [1]. It is a heterogeneous disorder with considerable differences in age of onset, morphological appearance and location, severity, comorbidity, and response to established treatments [2]. For example, early onset is generally associated with HLACw6, $-\mathrm{B} 13$ and $-\mathrm{B} 57$, while late onset is correlated with
HLA-Cw2 and -B27 [3] Environmental factors also play important roles in the pathogenesis of psoriasis. Triggering factors like smoking, excessive alcohol consumption, infections, stress and certain medications were found to be important for the initial manifestation and/or disease flares. [4-7]. Chronic plaque psoriasis is the most common type. About $18 \%$ to $21 \%$ of patients with psoriasis have distinctive nail changes, and nearly $11.2 \%$ to $14.3 \%$ develop seronegative inflammatory arthritis (psoriatic arthritis, 
PsA) in Asia [8, 9]. Furthermore, growing evidences have shown that psoriasis is associated with metabolic syndrome such as obesity, hypertension, diabetes, dyslipidemia, and psychiatric diseases $[10,11]$. The prevalence of psoriasis varies throughout the world, apparently reflecting differences in genetic and environmental factors. The incidence, clinical features, and comorbidities have been widely studied in the United States and Europe countries [12-15]. In Western countries, the prevalence is $2-3 \%$, across all ages [12]. Data on the epidemiology of psoriasis in Asian populations is scarce. It seems that the prevalence in Asian is lower than European and North Americans, basing on few published studies [12].

\section{RESULTS}

\section{General characteristics of psoriasis in China}

Of the 56 participating hospitals, 31 located in the North and 25 in the South (See Table 1). A total of 12,031 psoriasis patients were enrolled, 6005 of which in the North and 6026 in the south. The mean age of all patients was $39.42 \pm 18.42$ years old, and the ratio of male to female was 1.49:1. Among all patients, $23.1 \%$ had a positive family history of psoriasis (See Table 2).

As we can see from Table 3, 89.7\% of patients had received topical treatments and $79.8 \%$ had received systemic treatments. Scalp was the most common onset site (52.8\%, See Figure 1), while legs were the most common distribution sites of lesions $(77.7 \%$, See Table 4$)$. The difference in the mean age of disease onset was statistically significant between genders $(30.2 \pm 14.5$ years in males and $27.1 \pm 15.6$ in females, $P<0.05)$. And $52.3 \%$ of all patients had onset before 40 years old. There were significant differences between males and females in the distribution sites of lesions (See Table 4). Furthermore, $82.8 \%$ of patients suffered from pruritus, and among them $9.1 \%$ developed sleep disturbances and $26.9 \%$ had scratches.

\section{Phenotypes of psoriasis}

Majority of patients (96.5\%) were psoriasis vulgaris, $1.6 \%$ were pustular psoriasis , $0.7 \%$ were erythrodermic psoriasis, and 1.3\% were Psoriatic arthritis (See Table 3). Among 11751 patients with non-missing values on disease activity, $43.3 \%$ were in active stage, $34.1 \%$ in stable, $15.3 \%$ in resolving, and $7.3 \%$ in remitting stage.

\section{Disease severity of the patients}

The severity of our patients was evaluated on the basis of involved body surface area (BSA) and Psoriasis area and severity index (PASI) scoring method. The mean percentage of BSA that had skin lesions was 17.94
(SD20.06). Based on BSA involvement, $42.7 \%$ of patients were categorized as mild, $40.6 \%$ as moderate and $16.7 \%$ as severe. The mean PASI score was 18.70 (SD10.01), indicating that most patients attending hospitals had moderate-to-severe psoriasis (See Table 5).

\section{Comorbidities}

Among patients who took the tests, the most common comorbidity was hypertension $(16.4 \%)$, followed by hyperlipidemia $(13.7 \%)$, diabetes $(7.8 \%)$, and coronary heart disease $(2.4 \%$, See Table 6$)$.

\section{Characteristics of nail changes, joint involvement}

Nail changes were observed in $29.9 \%$ of psoriasis patients. Joint damages were observed in $6.2 \%$ of patients including $1.3 \%$ of patients with PsA (See Table 6).

\section{Factors causing relapse and/or aggravation}

As shown in Table 4, the most frequently reported cause of relapse or aggravation was season change $(60.2 \%)$, followed by psychological stress (34.5\%), sphagitis $(27.4 \%)$, dietary factors $(23.7 \%)$, alcohol consumption (18.4\%), medication (5.3\%), and smoking (5.2\%). Nearly half reports about weather as aggravating factor were related to winter season $(48.8 \%)$, followed by spring (23.1\%), autumn (17.1\%), and summer (8.4\%).

Aggravation of skin lesions due to sunlight exposure was reported by $11.6 \%$ of patients, whereas positive effects of sunlight were reported by $17.5 \%$ and no impact by $67.5 \%$ of patients. There was no significant difference of the impact of season change on relapse and aggravation between male and female. However, the impacts of mental stress, smoking, alcohol consumption and sphagitis were significantly different between genders (See Table 4). The longest mean time of remission was 15.46 months (SD40.28). A history of isomorphic effect (Koebner's phenomenon) was found in $39.4 \%$ of patients.

\section{DISCUSSION}

Up to now, only two population-based studies were conducted in China in 1984 and 2012, respectively $[16,17]$. These two studies report a lower prevalence of $0.12 \%$ and $0.47 \%$ of psoriasis in China, but details of clinical feature are less described. Similarly, there is also lack of population-based detailed descriptive study on clinical characteristic of psoriasis patients all over the world. This manuscript report a nationwide study focusing on clinical features, phenotypes, comorbidities, and etc. in the Han Chinese population. As far as we know, this is the largest study on clinical features, triggering factors 


\begin{tabular}{|c|c|c|c|}
\hline Cities & No.of hospitals & No.of cases & Location \\
\hline Beijing & 10 & 2513 & North \\
\hline Tianjing & 2 & 473 & North \\
\hline Dalian & 1 & 97 & North \\
\hline Xi'an & 1 & 300 & North \\
\hline Haerbing & 2 & 291 & North \\
\hline Changchun & 2 & 200 & North \\
\hline Shenyang & 2 & 329 & North \\
\hline Hohhot & 1 & 49 & North \\
\hline Shijiazhuang & 1 & 109 & North \\
\hline Zhengzhou & 2 & 756 & North \\
\hline Taiyuan & 3 & 763 & North \\
\hline Qingdao & 1 & 80 & North \\
\hline Jinan & 1 & 75 & North \\
\hline Lanzhou & 1 & 38 & North \\
\hline Yinchuan & 1 & 57 & North \\
\hline Xining & 1 & 99 & North \\
\hline Urumqi & 1 & 76 & North \\
\hline Hefei & 1 & 72 & South \\
\hline Nanjing & 1 & 1302 & South \\
\hline Wuxi & 2 & 372 & South \\
\hline Hangzhou & 3 & 289 & South \\
\hline Shanghai & 5 & 1797 & South \\
\hline Fuzhou & 1 & 12 & South \\
\hline Nanchang & 1 & 24 & South \\
\hline Wuhan & 1 & 493 & South \\
\hline Xianning & 1 & 265 & South \\
\hline Changsha & 1 & 75 & South \\
\hline Guangzhou & 2 & 104 & South \\
\hline Guilin & 1 & 18 & South \\
\hline Kunming & 1 & 26 & South \\
\hline Chengdu & 1 & 731 & South \\
\hline Chongqing & 1 & 77 & South \\
\hline Haikou & 1 & 69 & South \\
\hline Total & 56 & 12031 & \\
\hline
\end{tabular}

and comorbidities of Psoriasis among Han Chinese population.

In the study, the sex ratio was $1.49: 1$ which is consistent with findings of previous studies in China [16], while the sex ratio in German and UK was nearly 1:1. The difference could be due to that more male patients sought medical care for psoriasis. We found that female patients had disease onset at a significantly younger age than males, coincide with a recent study showing that median age at onset was 25 and 28 years among women and men respectively [18]. And over half had disease onset before the age of 40 . Scalp was the most frequently reported onset site $(52.8 \%)$, which is similar to studies in Japan (59.4\%) and the USA (52\% 56\%) $[5,19]$. In this study, over $70 \%$ of patients had severe psoriasis assessed by PASI scores. Genetic basis is involved in psoriasis, and family history is one of the strongest risk factors. Studies in Caucasians showed that about $30 \%$ of patients had an affected first-degree relative and their first-and second-degree relatives had an increased risk of psoriasis [20]. The risk of psoriasis vulgaris was found to be two to three times greater in 
Table 2: Summary of demographics of patient population

\begin{tabular}{|c|c|}
\hline Characteristics & $N=12031$ \\
\hline \multicolumn{2}{|l|}{$\operatorname{Sex} n(\%)$} \\
\hline Male & $7206(59.9)$ \\
\hline Female & $4825(40.1)$ \\
\hline \multicolumn{2}{|l|}{ Age, y } \\
\hline Min & 1 \\
\hline Max & 86 \\
\hline Mean (SD) & $39.42(18.4)$ \\
\hline \multicolumn{2}{|l|}{ Family history of psoriasis $n(\%)$} \\
\hline Family history of psoriasis & $2781(23.1)$ \\
\hline Relatives & $N=4995$ \\
\hline First degree relatives & $2323(46.5)$ \\
\hline Second degree relatives & $1538(30.8)$ \\
\hline Third degree relatives & $1134(22.7)$ \\
\hline \multicolumn{2}{|l|}{ History of smoking and alcohol $n(\%)$} \\
\hline Smoking history & $4023(33.4)$ \\
\hline Quit smoking & $936(7.8)$ \\
\hline Alcohol history & $2524(21.0)$ \\
\hline Alcohol history $>10 y r s$ & $1281(10.6)$ \\
\hline
\end{tabular}

monozygotic than in dizygotic twins [17, 21]. In our study, over $20 \%$ of patients had positive family history, which was more frequent in first-degree relatives than in secondand third-degree relatives. This is consistent with previous

Consistent with the finding of the 1984 nationwide survey in China, we found that most Chinese patients suffered from psoriasis vulgaris $(96.5 \%)$, of which plaque was the dominant type (51.1\%) [16]. When assessed by BSA involvement, more patients were categorized as having moderate-to-severe psoriasis in our study $(57.3 \%)$ than that in the 1984 nationwide survey (37.2) [16]. The difference may be partially explained by different study design and changes in environments and health-care seeking behaviors.

In our study, only $1.3 \%$ reported that they had ever been diagnosed with PsA. And joint damages were observed among $6.2 \%$ of all patients, which is lower than the prevalence $(5.8 \%)$ found in another Chinese study. However, PsA prevalence is much higher in Caucasians and other Asian population like Japanese and Korean $[8,9]$. This is probably due to the difference in genetic backgrounds and diagnostic criteria. On the other hand, since PsA was not diagnosed with serological tests and imaging examinations in our study, some early stage patients may be leave out, therefore, there might be an underestimate of PsA prevalence in the analyzed population.

In our study, over $80 \%$ of patients suffered from pruritus, which is similar to that among Italian psoriasis patients and much higher than German patients. High prevalence of pruritus found in our study represents great impact on the quality of life among psoriasis patients in China.
It is well known that a number of factors may trigger the onset and aggravation of psoriasis. Recent surveys from China have identified that infection, mental stress, medication, moisture, alcohol consumption, and smoking are important risk factors for psoriasis [2, 16, 23].

In the present study, the top three most frequently reported factors for relapse and aggravation were season $(60.2 \%)$, mental stress $(34.5 \%)$, and pharyngitis and tonsillitis $(27.4 \%)$. The 1984 nationwide survey also found weather conditions (32.9\%), infections $(22.4 \%)$ and mental factors $(12.2 \%)$ to be the most frequent causes of psoriasis deterioration. Since aggravation most frequently appears in winter and spring, it is thought that the disease is related to the decrease in temperature, humidity and daylight in these seasons.

Mental stress was found to be a primary aggravation factor. In another survey of psoriasis patients in China, $60.8 \%$ and $10.6 \%$ of patients believed that they had social and career development problems directly related to psoriasis [17]. A population-based study showed that history of psoriasis was independently associated with increased risk of major depression among individuals with limited or extensive psoriasis [24]. These findings suggest that it is important to attend to patients' mental stress and give psychological intervention. Much more people reported alcohol as aggravation factors in our survey than in the 1984 survey, which is probably owing to the remarkable changes in Chinese people's life style.

We also fount that women often reported mental stress and sphagitis as aggravation factors, while men reported smoking and alcohol more often. This suggests that physicians should pay attention to different factors 
Table 3: Clinical features and treatment history of patients

\begin{tabular}{|c|c|}
\hline Characteristics & No. of cases $(\%)$ \\
\hline Total & $N=12031$ \\
\hline \multicolumn{2}{|l|}{ Treatment history } \\
\hline Systemic treatments & $9600(79.8)$ \\
\hline $\mathrm{TCM}^{a}$ & $8661(72.0)$ \\
\hline Vitamin A derivatives & $2604(21.6)$ \\
\hline Immune Depressants & $1297(10.8)$ \\
\hline Glucocorticoids & $1577(13.1)$ \\
\hline Topical treatments & 10787 (89.7) \\
\hline Glucocorticoids & $9113(75.7)$ \\
\hline Vitamin D3 analog & $3634(30.2)$ \\
\hline Tazarotene & $2976(24.7)$ \\
\hline $\mathrm{TCM}^{a}$ & $2802(23.3)$ \\
\hline Salicylic Acid & $2295(19.1)$ \\
\hline Other Therapy & $2634(21.9)$ \\
\hline Photo Therapy & $2220(18.5)$ \\
\hline Hydro Therapy & $575(4.8)$ \\
\hline \multicolumn{2}{|l|}{ Phenotypes } \\
\hline Psoriasis vulgaris & $11606(96.5)$ \\
\hline Guttate type & $3503(29.1)$ \\
\hline plaque type & $6147(51.1)$ \\
\hline mixed type & $1956(16.3)$ \\
\hline Pustular psoriasis & $189(1.6)$ \\
\hline palms and soles type & $41(0.3)$ \\
\hline generalized type & $148(1.2)$ \\
\hline Erythrodermic psoriasis & $83(0.7)$ \\
\hline Psoriatic arthritis ${ }^{b}$ & $153(1.3)$ \\
\hline
\end{tabular}

$a$, traditional Chinese medicine.

$b$, obtained from the patients history on a questionnaire.

and give appropriate advice when dealing with female and male patients.

Metabolic syndrome is a clinical syndrome characterized by a combination of multiple metabolic diseases. Recent studies from China and western countries have shown that patients with psoriasis had an increased prevalence of metabolic syndrome which may be linked to disease pathophysiology $[3,25,26]$. We found that $5.2 \%$ of psoriasis patients were obese, while latest data from a large registry (PSOLAR) in Caucasians showed that $80 \%$

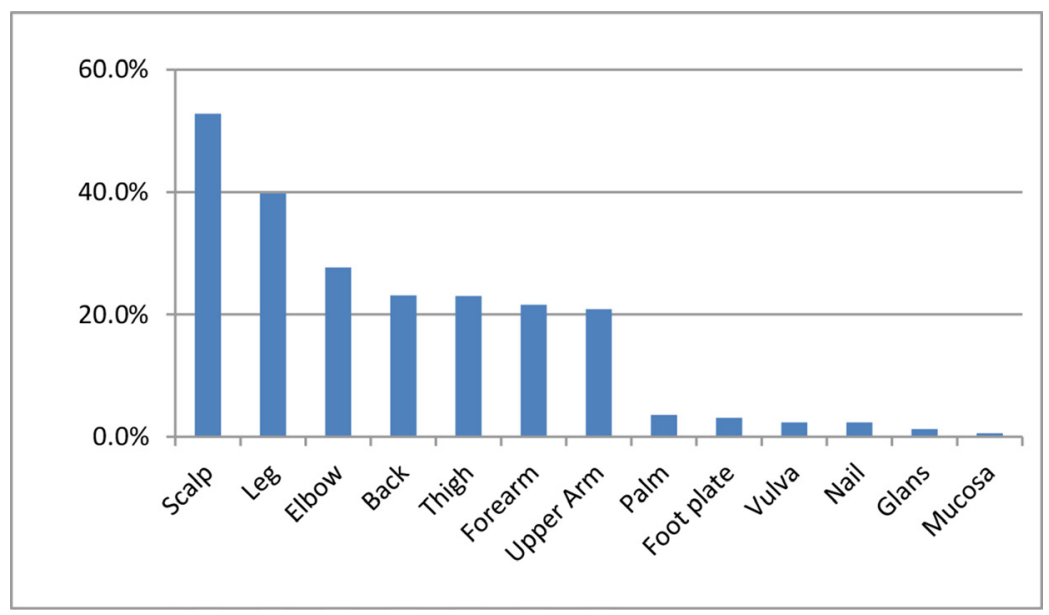

Figure 1: Onset position of patients. 
Table 4: Comparison of lesions distribution and triggering factors between genders

\begin{tabular}{|c|c|c|c|c|}
\hline & Total $N=12031 n(\%=n / N)$ & Male $\left(N_{1}=7206\right) n_{1}\left(\%=n_{1} / N_{1}\right)$ & Female $\left(N_{2}=4825\right) n_{2}\left(\%=n_{2} / N_{2}\right)$ & $p$ \\
\hline \multicolumn{5}{|c|}{ Triggering factors } \\
\hline Season & $7243(60.2)$ & $4388(60.9)$ & $2861(59.3)$ & 0.203 \\
\hline stress & $4151(34.5)$ & $2414(33.5)$ & $1790(37.1)$ & $<0.001$ \\
\hline Smoking & $626(5.2)$ & $533(7.4)$ & $92(1.9)$ & $<0.001$ \\
\hline Alcohol & $2214(18.4)$ & 1794 (24.9) & $405(8.4)$ & $<0.001$ \\
\hline Sphagitis & $3296(27.4)$ & $1816(25.2)$ & $1486(31.0)$ & $<0.001$ \\
\hline \multicolumn{5}{|c|}{ Lesions distribution } \\
\hline Leg & 9348 (77.7) & $5355(74)$ & $3993(83)$ & $<0.001$ \\
\hline Scalp & $9024(75.0)$ & $5797(80)$ & $3227(67)$ & $<0.001$ \\
\hline Elbow & $8069(67.1)$ & $4757(66)$ & $3312(69)$ & 0.183 \\
\hline Thigh & $8042(66.8)$ & $4558(63)$ & $3484(72)$ & $<0.001$ \\
\hline Forearm & $7620(63.3)$ & $4402(61)$ & $3218(67)$ & $<0.05$ \\
\hline Back & $7602(63.2)$ & $4173(58)$ & $3429(71)$ & $<0.001$ \\
\hline Upper arm & $7298(60.7)$ & $4104(57)$ & $3194(66)$ & $<0.001$ \\
\hline Waist & $6639(55.2)$ & $3719(52)$ & $2920(61)$ & $<0.001$ \\
\hline Abdomen & $6405(53.2)$ & $3442(48)$ & $2963(61)$ & $<0.001$ \\
\hline Knee & $6293(52.3)$ & $363550)$ & $2658(61)$ & $<0.05$ \\
\hline Bottom & $5867(48.8)$ & $3303(46)$ & $2564(55)$ & $<0.001$ \\
\hline Chest & $5782(48.1)$ & $3273(45)$ & $2509(53)$ & $<0.001$ \\
\hline Ear canal & $3863(32.1)$ & $2374(33)$ & $1489(52)$ & 0.085 \\
\hline Palm & $1244(10.3)$ & $733(10)$ & $511(31)$ & 0.505 \\
\hline Foot Plate & $1170(9.7)$ & $667(9)$ & $503(11)$ & 0.055 \\
\hline perineum $^{a}$ & $1145(9.5)$ & $680(9)$ & $465(10)$ & 0.738 \\
\hline Mucosa $a^{b}$ & $186(1.5)$ & $123(2)$ & $63(1)$ & 0.085 \\
\hline Glans & $526(4.4)$ & $526(7)$ & & \\
\hline
\end{tabular}

Chi-square test, significant at $p<0.05$.

$a$, include scrotum in men.

$b$, especially indicate lip mucosa.

Table 5: Disease severity based on the BSA and PASI score

\begin{tabular}{lll}
\hline & $\boldsymbol{N}$ & $\%$ \\
\hline Mean percentage of skin lesion on body surface area (SD) & $17.94 \pm 20.06$ & 42.7 \\
Mild & 4884 & 40.6 \\
Moderate & 4652 & 16.7 \\
Severe & 1914 & \\
Mean PASI scores of skin lesion (SD) & $18.70 \pm 10.01$ & 15.3 \\
Mild & 1736 & 13.5 \\
Moderate & 1532 & 71.1 \\
Severe & 8047 & \\
\hline
\end{tabular}

BSA, body surface area, grouped by mild $(<10 \%)$, moderate $(10 \% \sim 30 \%)$, severe $(>30 \%)$.

PASI, Psoriasis Area and Severity Index, grouped by mild $(<8)$, moderate $(8 \sim 12)$, severe $(>12)$.

of psoriasis patients were obese [26]. In our study, the prevalence of metabolic comorbidities were $10.2 \%, 5.9 \%$ and $4.3 \%$ respectively for hypertension, hyperlipidemia and diabetes, which is much lower than that found in France $(26 \%, 27.5 \%$ and $11.0 \%$ for hypertension, hyperlipidemia and diabetes respectively) [27]. 
Table 6: Characteristics of disorders on nail, joint and metabolism of patients

\begin{tabular}{|c|c|}
\hline Characteristics & $N=12031[\%=n / N]$ \\
\hline Nail Damage $n(\%)$ & $3592(29.9)$ \\
\hline Nail pitting & 2167 (18.) \\
\hline Oil drops & $1765(14.7)$ \\
\hline Subungual hyperkeratosis & $1395(11.6)$ \\
\hline Longitudinal ridging of nails & $1326(11.0)$ \\
\hline Onycholysis & $856(7.1)$ \\
\hline Onychomadesis & $300(2.5)$ \\
\hline Joint Damages $^{a} n(\%)$ & $740(6.2)$ \\
\hline Digital joints & $406(3.4)$ \\
\hline Knee joint & $356(3.0)$ \\
\hline Toe joint & $190(1.6)$ \\
\hline Ankle joint & $131(1.1)$ \\
\hline Elbow Joint & $114(0.9)$ \\
\hline Wrist joint & $114(0.9)$ \\
\hline Vertebral column & $94(0.8)$ \\
\hline \multicolumn{2}{|l|}{ Joint Symptoms } \\
\hline Red & $207(1.7)$ \\
\hline Swelling & $311(2.6)$ \\
\hline Pain & $588(4.9)$ \\
\hline Deformity & $222(0.3)$ \\
\hline Weight $n(\%)$ & $N=10955$ \\
\hline Obese & $574(5.2)$ \\
\hline \multicolumn{2}{|c|}{ Clinical and Laboratory parameters abnormal $n(\%)$} \\
\hline Blood pressure & $N=12031$ \\
\hline Abnormal $n(\%)$ & $1976(16.4)$ \\
\hline Liver Functional Test & $N=6286$ \\
\hline Abnormal n (\%) & $224(3.6)$ \\
\hline Renal Functional Tests & $N=6120$ \\
\hline Abnormal $n(\%)$ & $91(1.5)$ \\
\hline Lipid Test & $N=6001$ \\
\hline Increased Blood lipid $n(\%)$ & $824(13.7)$ \\
\hline Blood Glucose Test & $N=\mathbf{5 9 7 8}$ \\
\hline Abnormal $n(\%)$ & $468(7.8)$ \\
\hline
\end{tabular}

$a$, according to the Moll and Wright criteria, other joint damage is defined as redness and swelling, pain or deformation in a joint last for more than 1 month.

At last and notably, there were several limitations in our study. Firstly, due to objective conditions it is inappropriate and impractical to refer all psoriasis patients accepted serological and imaging examination to confirm the diagnosis of PsA, the questionnaire just inquiry about the joint symptoms and have ever been diagnosed with psoriatic arthritis. So we were unable to determine the accurate prevalence of PsA in the sample. Secondly, many patients were not willing to undergo blood tests so that we only analyzed a subset of the sample for the prevalence of metabolic diseases. The prevalence of metabolic diseases may be underestimated if more patients who were not tested had those metabolic conditions. Further studies are warranted to establish simple and precise PsA and metabolic disease evaluation system for clinical use.

In summary, our study was done with a large sample size. We found that there were many similarities in onset age, onset site, clinical phenotypes and aggravation factors between Han Chinese and Caucasian psoriasis patients. However, the prevalence of PsA and metabolic diseases were much lower among Chinese psoriasis patients than Caucasians which provides some insights into the impact 
of environmental and/or genetic factors. Moreover, since mental factors play a more and more important role in the induction of the disease, physicians should take patients' mental status seriously in the process of medical activities.

\section{MATERIALS AND METHODS}

\section{Participant recruitment and study procedure}

Under the coordination of the Psoriasis Investigation Group of the China Dermatologist Association from November 2009 to June 2010, a nationwide survey of psoriasis patients was conducted at the department of dermatology of 56 hospitals in 33 cities across China. The stratified sampling method was used to select cities. Patients of Han ethnic group who were diagnosed with psoriasis by a dermatologist at participating hospitals were recruited in the study by convenience sampling method. After informed consent was obtained, patients who were willing to participate were enrolled and interviewed using a standard questionnaire. The following information was collected: demographics, family history, history of smoking and alcohol intake, prior treatments, disease status including onset sites, onset age, causes of relapse or flare episodes, systemic symptoms and concomitant conditions during the course of the disease. Medical history of hypertension, hyperlipidemia, diabetes and coronary heart disease that were diagnosed by physicians were also inquired. All patients underwent physical examinations including measurements of weight, height, waist circumference and blood pressure. Dermatological examinations were conducted to assess morphological subtypes (guttate, plaque, combined type psoriasis, pustular psoriasis, and erythrodermic psoriasis).

Body surface area (BSA) and psoriasis area severity index (PASI) were used to evaluate the disease severity. A visual inspection of oral mucosa, genitals and nails was also included.

For patients who were willing to give blood samples, tests for ALT, AST, blood urea nitrogen, serum creatinine, cholesterol, triglycerides, and fasting blood glucose performed. Prior to the survey, all physicians involved in the study at participating hospitals were trained according to the same training manual on case definition and conducting examinations. Physicians were required to check questionnaires for missed items and logical errors right after each interview and make revisions accordingly.

\section{Measures}

Psoriasis activity at the time of presentation was graded according to patients' self-assessment as active (continuous appearance of new lesions and no resolution of older ones), stable (persistence of existing lesions), resolving (improvement or disappearance of lesions), and remitting (almost none residual lesions).
Psoriatic arthritis incidence obtained from the patients history on a questionnaire According to Moll and Wright criteria, other joint damage is defined as redness and swelling, pain or deformation in a joint last for more than 1 month, confirmed by physical examination and medical records [19]. The diagnosis of metabolic comorbidities was mainly determined by medical history and examination in the survey. Abnormal metabolic values were defined as the following criteria: abdominal obesity (waist circumference $>102 \mathrm{~cm}$ in men and $>88 \mathrm{~cm}$ in women), hypertriglyceridemia ( $\geq 150 \mathrm{mg} / \mathrm{dL})$, low levels of high-density lipoprotein cholesterol $(<40 \mathrm{mg} / \mathrm{dL}$ in men and $<50 \mathrm{mg} / \mathrm{dL}$ in women), high blood pressure $(\geq 140 / 90 \mathrm{~mm} \mathrm{Hg}$ ), and high fasting glucose levels $(\geq$ $100 \mathrm{mg} / \mathrm{dL})$.

\section{Statistical analysis}

A statistician who was not involved in data collection for the study performed statistical evaluation independently using SPSS17.0 software. All patients were included in the statistical analysis. Descriptive statistics, 2 tailed $t$-test and chi-square test were appropriately used for the analysis of the data.

\section{ACKNOWLEDGMENTS AND FUNDING}

This epidemiologic investigation into psoriasis was funded by Leo Pharmaceutical Co., Shanghai, China. And this work was supported by CAMS Innovation Fund for Medical Sciences (2016-12M-1-005). We extend our sincere thanks to Dr. Peter Pothula,BioQuest for his valuable editorial guidance and Dr. Stephan Weidinger, Kiel, for critical reading of the manuscript.

We also wish to thank the other study investigators in this nation-wide epidermiology survey: Qiuning Sun, Ping Wang, Guang Zhao, Jianzhong Zhang, Liming Xu, Hengjing Li, Ruoyu Li, Lingfeng Li, Jianming Chang, Yanli He, Wali Liu, WeimingXu, Yingxian Chu, Zhirong Yao, Jun Gu, Xianglong Pan, Bing Li, Shanshan Li, Fuqin Li, XinghuaGao, YuzhengShu, Tienan Li, Zhenglu Li, TianwengGao, Xiaowei Qing, Yuping Li, Lijia Yang, Baoxi Wang, Sheng Yang, YiqunDuan, Qianjing Lu, Ping Fan, Qun Wang, Kang Zheng, Wei Lai, Yongjian Qin, Bo Cheng, Hui-Lan Yang, Chunyang Li, Xuzhuan Zhao, Hong Fang, Bingxu Li, FeiHao, Jing Chen, Li He, Rina Wu, Jun Liu, ZhichengLuo, Qiao Liu, Li Chen.

\section{CONFLICTS OF INTEREST}

The authors state no conflicts of interest.

\section{REFERENCES}

1. Elder JT, Bruce AT, Gudjonsson JE, Johnston A, Stuart PE, Tejasvi T, Voorhees JJ, Abecasis GR, Nair RP. Molecular 
dissection of psoriasis: integrating genetics and biology. J Invest Dermatol. 2010; 130:1213-26.

2. Wang H, Zhang X, Yang S. [Study on the risk factors of psoriasis]. [Article in Chinese]. Zhonghua Liu Xing Bing Xue Za Zhi. 2001; 22:215-18.

3. Gupta R, Debbaneh MG, Liao W. Genetic Epidemiology of Psoriasis. Curr Dermatol Rep. 2014; 3:61-78.

4. Herron MD, Hinckley M, Hoffman MS, Papenfuss J, Hansen CB, Callis KP, Krueger GG. Impact of obesity and smoking on psoriasis presentation and management. Arch Dermatol. 2005; 141:1527-34.

5. Marino MG, Carboni I, De Felice C, Maurici M, Maccari F, Franco E. Risk factors for psoriasis: a retrospective study on 501 outpatients clinical records. Ann Ig. 2004; 16:753-58.

6. Cohen AD, Van-Dijk D, Naggan L, Vardy DA. Effectiveness of climatotherapy at the Dead Sea for psoriasis vulgaris: A community-oriented study introducing the 'Beer Sheva Psoriasis Severity Score'. J Dermatolog Treat. 2005; 16:308-13.

7. Naldi L, Chatenoud L, Linder D, Belloni Fortina A, Peserico A, Virgili AR, Bruni PL, Ingordo V, Lo Scocco G, Solaroli C, Schena D, Barba A, Di Landro A, et al. Cigarette smoking, body mass index, and stressful life events as risk factors for psoriasis: results from an Italian case-control study. J Invest Dermatol. 2005; 125:61-67.

8. Shin D, Kim HJ, Kim DS, Kim SM, Park JS, Park YB, Lee MG. Clinical features of psoriatic arthritis in Korean patients with psoriasis: a cross-sectional observational study of 196 patients with psoriasis using psoriatic arthritis screening questionnaires. Rheumatol Int. 2016; 36:207-12.

9. Ohara Y, Kishimoto M, Takizawa N, Yoshida K, Okada M, Eto H, Deshpande GA, Ritchlin CT, Tanaka A, Higashiyama M, Matsui K, Tsuji S. Prevalence and Clinical Characteristics of Psoriatic Arthritis in Japan. J Rheumatol. 2015; 42:1439-42.

10. Armstrong AW, Harskamp CT, Armstrong EJ. Psoriasis and metabolic syndrome: a systematic review and meta-analysis of observational studies. J Am Acad Dermatol. 2013; 68:654-62.

11. Henseler T, Christophers E. Disease concomitance in psoriasis. J Am Acad Dermatol. 1995; 32:982-86.

12. Parisi R, Symmons DP, Griffiths CE, Ashcroft DM, Identification and Management of Psoriasis and Associated ComorbidiTy (IMPACT) project team. Global epidemiology of psoriasis: a systematic review of incidence and prevalence. J Invest Dermatol. 2013; 133:377-85.

13. Phan C, Sigal ML, Lhafa M, Barthélémy H, Maccari F, Estève E, Reguiai Z, Perrot JL, Chaby G, Maillard H, Bégon E, Alexandre M, Toussaint P, et al. Metabolic comorbidities and hypertension in psoriasis patients in France. Comparisons with French national databases. Ann Dermatol Venereol. 2016; 143:264-74.
14. Merola JF, Li T, Li WQ, Cho E, Qureshi AA. Prevalence of psoriasis phenotypes among men and women in the USA. Clin Exp Dermatol. 2016; 41:486-89.

15. Qureshi AA, Choi HK, Setty AR, Curhan GC. Psoriasis and the risk of diabetes and hypertension: a prospective study of US female nurses. Arch Dermatol. 2009; 145:379-82.

16. Shao C, Zhang G, Bao Y, Jiang Z, Han G, Gu H. Epidemiology of psoriasis in China in 1984. Zhonghua Liu Xing Bing Xue Za Zhi. 1984; 19:253-61.

17. Ding X, Wang T, Shen Y, Wang X, Zhou C, Tian S, Liu Y, Peng G, Zhou J, Xue S, Wang R, Tang Y, Meng X, et al. Prevalence of psoriasis in China: a population-based study in six cities. Eur J Dermatol. 2012; 22:663-67.

18. Lønnberg AS, Skov L, Duffy DL, Skytthe A, Kyvik KO, Pedersen OB, Thomsen SF. Genetic Factors Explain Variation in the Age at Onset of Psoriasis: A Population-based Twin Study. Acta Derm Venereol. 2016; 96:35-38.

19. Moll JM, Wright V. Psoriatic arthritis. Semin Arthritis Rheum. 1973; 3:55-78.

20. Andressen C, Henseler T. [Inheritance of psoriasis. Analysis of 2035 family histories]. [Article in German]. Hautarzt. 1982; 33:214-17.

21. Brandrup F, Holm N, Grunnet N, Henningsen K, Hansen HE. Psoriasis in monozygotic twins: variations in expression in individuals with identical genetic constitution. Acta Derm Venereol. 1982; 62:229-36.

22. Shu Y, Gao B, Song W. The study of social mental factors in the influence of psoriasis patients condition. Zhonghua Pifuke Zazhi. 1997; 30:114-15.

23. Zhang X, Wang H, Te-Shao H, Yang S, Wang F. Frequent use of tobacco and alcohol in Chinese psoriasis patients. Int $\mathrm{J}$ Dermatol. 2002; 41:659-62.

24. Cohen BE, Martires KJ, Ho RS. Psoriasis and the Risk of Depression in the US Population: National Health and Nutrition Examination Survey 2009-2012. JAMA Dermatol. 2016; 152:73-79.

25. Davidovici BB, Sattar N, Prinz J, Puig L, Emery P, Barker JN, van de Kerkhof P, Ståhle M, Nestle FO, Girolomoni G, Krueger JG. Psoriasis and systemic inflammatory diseases: potential mechanistic links between skin disease and comorbid conditions. J Invest Dermatol. 2010; 130:1785-96.

26. Gisondi P, Tessari G, Conti A, Piaserico S, Schianchi S, Peserico A, Giannetti A, Girolomoni G. Prevalence of metabolic syndrome in patients with psoriasis: a hospitalbased case-control study. Br J Dermatol. 2007; 157:68-73.

27. Prignano F, Ricceri F, Pescitelli L, Lotti T. Itch in psoriasis: epidemiology, clinical aspects and treatment options. Clin Cosmet Investig Dermatol. 2009; 2:9-13. 